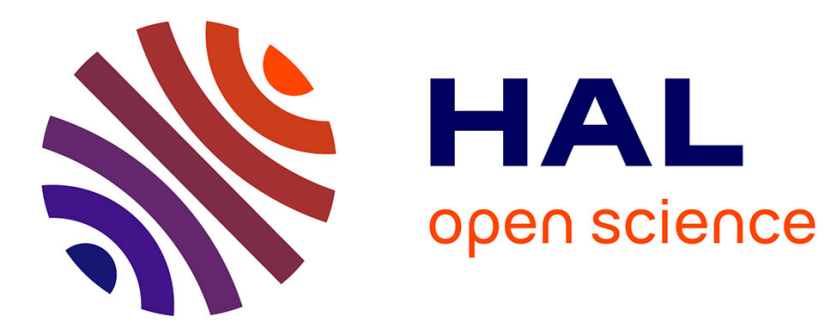

\title{
Deep red luminescent hybrid copolymer materials with high transition metal cluster content
}

Maria Amela-Cortes, Alexandre Garreau, Stéphane Cordier, Eric Faulques, Jean-Luc Duvail, Yann Molard

\section{- To cite this version:}

Maria Amela-Cortes, Alexandre Garreau, Stéphane Cordier, Eric Faulques, Jean-Luc Duvail, et al.. Deep red luminescent hybrid copolymer materials with high transition metal cluster content. Journal of Materials Chemistry C, 2014, 2, pp.1545-1552. 10.1039/C3TC31309C . hal-01016524

\section{HAL Id: hal-01016524 \\ https://hal.science/hal-01016524}

Submitted on 30 Jun 2014

HAL is a multi-disciplinary open access archive for the deposit and dissemination of scientific research documents, whether they are published or not. The documents may come from teaching and research institutions in France or abroad, or from public or private research centers.
L'archive ouverte pluridisciplinaire HAL, est destinée au dépôt et à la diffusion de documents scientifiques de niveau recherche, publiés ou non, émanant des établissements d'enseignement et de recherche français ou étrangers, des laboratoires publics ou privés. 


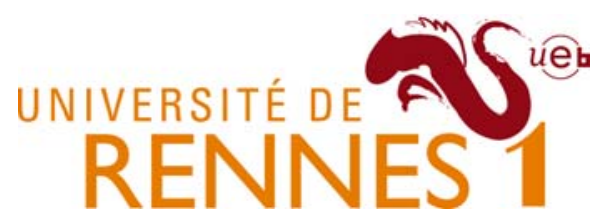

This is the author's final draft post-refeering (post-print)

Find more peer-reviewed articles on our open access repository:

http://hal-univ-rennes1.archives-ouvertes.fr/ 


\title{
Deep red luminescent hybrid copolymer materials with high transition metal cluster content $\dagger$
}

\author{
Maria Amela-Cortes, ${ }^{a}$ Alexandre Garreau, ${ }^{\text {b }}$ Stéphane Cordier, ${ }^{a}$ Eric Faulques, ${ }^{b}$ \\ Jean-Luc Duvail ${ }^{\mathrm{b}}$ and Yann Molard ${ }^{\star a}$
}

\begin{abstract}
The hybrid strategy is a powerful approach to design functional materials by combining inorganic dyes with an organic matrix. However, introducing high contents of inorganic species within the hybrid material is a real challenge that requires a perfect balance between the interactions of both components to avoid mainly phase segregation problems. Based on our demonstration on an anionic molybdenum cluster, we present a general method to introduce high contents of such class of nanometre sized inorganic molecular deep red dyes in a polymer matrix. Our strategy exploits the physical interactions between the organic and inorganic parts of the hybrid material and allows a high cluster rate to be introduced (up to $50 \mathrm{wt} \%$ ) in the polymer matrix. The resulting hybrids are remarkably stable even after several months of ageing. Moreover, the Mo clusters maintain their intrinsic deep red luminescence properties while the polymer organic matrix fully maintains its processability, thanks to the di-anionic character of the $\mathrm{Mo}_{6}$ clusters. Such materials show promising prospects in applications needing deep red emitters.
\end{abstract}

\section{Introduction}

Photoluminescent materials are playing a major role in applications related to photonics, optoelectronics or lighting. ${ }^{1}$ Combining them with polymers allows the design of easy-toshape functional materials with enhanced application versatility. ${ }^{2}$ Besides the all-organic strategy, the elaboration of materials with tailored absorption and emission properties by using a hybrid pathway (i.e. combining inorganic dyes with an organic polymer matrix) is a very powerful and promising approach. $\mathrm{ZnO},{ }^{3} \mathrm{CdSe}$ quantum dots, ${ }^{4}$ polyoxometalates, ${ }^{5,6}$ gold nanoparticles ${ }^{7}$ or lanthanide complexes ${ }^{8}$ are some examples of nanometric dyes among others which have been successfully incorporated in a polymer matrix. However, achieving homogeneous hybrid polymer materials with high inorganic content without altering the processability of the organic matrix is still challenging. It requires a perfect balance between the interactions of both components to avoid (i) any segregation that would end up with scattering problems and loss of transparency, (ii) high crosslinking ability of the inorganic dyes to prevent significant changes of the physical properties of the polymer matrix. Octahedral metal atom clusters are inorganic

${ }^{a}$ UMR Institut des Sciences Chimiques de Rennes UR1-CNRS 6226, Université de Rennes 1, Campus de Beaulieu, CS 74205, F-35042 Rennes Cedex, France. E-mail: yann.molard@univ-rennes1.fr

${ }^{b}$ Institut des Matériaux Jean Rouxel, CNRS, IMN, UMR 6502 CNRS-Université de Nantes, F-44322 Nantes, France

$\dagger$ Electronic supplementary information (ESI) available: TGA and DTG thermograms, emission decay profiles, CIE coordinate values at various temperatures and EDAX analysis of PM10. See DOI: 10.1039/c3tc31309c molecular species obtained via high temperature solid state chemistry routes and containing metal atoms linked together by metal-metal bonds. Many routes ${ }^{9,10}$ afford now soluble discrete $\left[\mathrm{M}_{6} \mathrm{X}_{8}^{\mathrm{i}} \mathrm{X}_{6}^{\mathrm{a}}\right]^{2-}$ units $(\mathrm{X}=$ halogen $)$ that exhibit, either in the liquid or solid state, specific electronic, magnetic, and photophysical properties related to the number of metallic electrons available for metal-metal bonds. ${ }^{\mathbf{1 1}}$ In particular, they are highly emissive in the red-NIR region with photoluminescence quantum yields of up to 0.59, displaying long excited-state lifetimes. ${ }^{12-14}$ These well-defined hexanuclear quantum dots are peculiar functional building blocks usable for the design of liquid crystalline materials, ${ }^{15}$ supramolecular architectures, ${ }^{\mathbf{1 6}}$ polymeric frameworks, ${ }^{17}$ or nanomaterials. ${ }^{18}$ Few examples are found in the literature where hybrid polymers showing high and stable deep red luminescence properties are obtained by incorporation of octahedral clusters. The direct incorporation of inorganic species in the polymer has to be circumvented because strong interactions between the organic and inorganic entities constituting the hybrid materials are a pre-requisite to obtain fully homogeneous and stable hybrid materials. ${ }^{19}$ The usual methodology up to now has been based on the covalent grafting of up to six polymerizable units in apical positions of the inorganic cluster core. Golden et al. ${ }^{20}$ were the first to study the introduction of octahedral metal clusters in a polymer host by using a "monomer as solvent" approach. They introduced $\mathrm{a} \mathrm{Mo}_{6}$ cluster in a polymer matrix by substitution of six weakly bound apical triflate ligands in $\left[\mathrm{Mo}_{6} \mathrm{Cl}_{8}(\mathrm{OTf})_{6}\right]^{2-}$ with $\mathrm{N}$-vinylimidazole (NVI) monomer moieties. After substitution, the modified cluster was dispersed in NVI and copolymerised. Surprisingly, the luminescence 
properties of this first hybrid were not reported. Adamenko et $a .^{21}$ used the same approach by replacing some of the six labile trifluoroacetate ligands of $\left[\mathrm{Mo}_{6} \mathrm{Cl}_{8}\left(\mathrm{CF}_{3} \mathrm{COO}\right)_{6}\right]^{2-}$ with acrylate moieties to obtain $\left[\mathrm{Mo}_{6} \mathrm{Cl}_{8}\left(\mathrm{CF}_{3} \mathrm{COO}\right)^{6-n}\left(\mathrm{CH}_{2}=\right.\right.$ (HCOO $\left.)_{n}\right]^{2-} n=1-3$ and copolymerized it with methacrylic acid. In this case, the cluster luminescence properties were lost after aging because of some degradation induced probably by the lability of the trifluoroacetate groups. Shriver et al. ${ }^{22}$ coordinated $\left[\mathrm{Mo}_{6} \mathrm{Cl}_{8}(\mathrm{OTf})_{6}\right]^{2-}$ and $\left[\mathrm{Mo}_{6} \mathrm{Cl}_{8}{ }_{8} \mathrm{Cl}^{\mathrm{a}}{ }_{4}(\mathrm{EtOH})^{\mathrm{a}}{ }_{2}\right]$ to poly(vinylpyridine) to produce crosslinked materials. Transient emission spectroscopy revealed that the polymer bound hexatriflate cluster lacks the luminescence properties characteristic of many $\left[\mathrm{Mo}_{6} \mathrm{Cl}_{8}\right]^{4+}$ based clusters while the other one displays luminescence. However, unswellable materials with no discernible $T_{\mathrm{g}}$ were obtained even at low cluster/polymer ratios indicating a high degree of crosslinking and thus a lack of processability. Very recently, we succeeded in introducing hexafunctionalized $\mathrm{Mo}_{6}$ clusters in a PMMA matrix. ${ }^{23}$ However, even though the luminescence properties of the starting cluster were maintained within the copolymer, its high crosslinking abilities prevent its introduction in high content. Oxygen sensors taking advantage of the ${ }^{3} \mathrm{O}_{2}$ cluster red emission quenching abilities were described by Nocera et al. ${ }^{24}$ These systems were obtained starting from the molybdenum chloride cluster precursor $\mathrm{Mo}_{6} \mathrm{Cl}_{12}$ that reacted with either poly(vinylpyridine) or poly[1-trimethylsilyl-1-propyne] polymers to afford crosslinked polymers. We also observed the high crosslinking ability of bifunctionalized octahedral clusters when we copolymerized $\left.\left[\mathrm{Re}_{6} \mathrm{Se}_{8} \text { (tert-butylpyridine }\right)_{4}\left(\mathrm{CH}_{2}=\mathrm{C}\left(\mathrm{CH}_{3}\right) \mathrm{COO}\right)_{2}\right]$ with methylmethacrylate. ${ }^{25}$ This crosslinking ability was avoided by the process reported by Z. Zheng et al. when they introduced a monofunctionalized $\mathrm{Re}_{6}$ cluster in the side chain of polystyrene strands by copolymerization between styrene and a vinylpyridine coordinated to the cluster. ${ }^{26}$ However, the luminescence properties of this hybrid were not reported probably because the presence of phosphine ligands on the five remaining $\operatorname{Re}_{6}$ cluster apical positions induces a drastic decrease of its photoluminescence quantum yield. Therefore, we can state from these previous studies that a universal technique allowing the combination of the native cluster luminescence properties with the shaping abilities of organic polymers still needs to be discovered to greatly enhance the applicative potential of such hybrid material. Based on our demonstration on $\left[\mathrm{Mo}_{6} \mathrm{Br}_{8}^{\mathrm{i}} \mathrm{Br}_{6}^{\mathrm{a}}\right]^{2-}$ anionic transition metal atom cluster compounds, we present in this work a general method to introduce in a polymer matrix high content of such class of nanometre sized inorganic molecular deep red dyes.

\section{Experimental section}

\subsection{Synthesis}

Starting materials were purchased from Alfa Aesar or Aldrich. Methacrylic acid and methyl methacrylate were distilled before use. Azobisisobutyronitrile (AIBN) was purified via recrystallisation in ether prior to use. The $\left(\mathrm{Cs}^{+}\right)_{2}\left[\mathrm{Mo}_{6} \mathrm{Br}_{8} \mathrm{Br}_{6}\right]^{2-}$ precursor was obtained by a reported procedure. ${ }^{10} \mathrm{NMR}$ experiments were realized on a Bruker Ascend $400 \mathrm{MHz}$ NMR spectrometer. Elemental analysis was performed with a Flash EA1112 microanalyzer at Centre Régional de Mesures Physiques de l'Ouest (CRMPO).

Dodecyl(11-(methacryloyloxy)undecyl)dimethylammonium bromide. The ammonium salt was obtained in two steps starting from methacryloyl chloride and bromoundecanol. Methacryloyl chloride (0.92 g, $8.8 \mathrm{mmol}$ ) was dissolved in $10 \mathrm{~mL}$ dry THF and added dropwise to a stirred solution of 11-bromo-1-undecanol (2.0 $\mathrm{g}, 8.0 \mathrm{mmol})$ and triethylamine $(0.87 \mathrm{~g}, 8.8 \mathrm{mmol})$ in $30 \mathrm{~mL}$ of dry THF. The mixture was stirred at $60{ }^{\circ} \mathrm{C}$ for $2.5 \mathrm{~h}$. After cooling, the precipitated triethylamine hydrochloride was filtered. The filtrate was evaporated and purified by column chromatography $\left(\mathrm{CH}_{2} \mathrm{Cl}_{2}\right)$. The 11-bromoundecyl methacrylate was obtained as a colourless liquid (yield $=80 \%) .{ }^{1} \mathrm{H}-\mathrm{NMR}\left(400 \mathrm{MHz}, \mathrm{CDCl}_{3}\right): 6.09(\mathrm{~d}, 1 \mathrm{H}$, $\mathrm{CH}=\mathrm{H}), 5.54(\mathrm{~d}, 1 \mathrm{H}, \mathrm{CH}=\mathrm{C}), 4.13\left(\mathrm{t}, 2 \mathrm{H},-\mathrm{CH}_{2}-\mathrm{O}\right), 3.40(\mathrm{t}, 2 \mathrm{H}$, $\left.-\mathrm{CH}_{2}-\mathrm{Br}\right), 1.94\left(\mathrm{~s}, 3 \mathrm{H},-\mathrm{CH}_{3}-\mathrm{C}\right), 1.87-1.84\left(\mathrm{~m}, 2 \mathrm{H},-\mathrm{CH}_{2}-\mathrm{CH}_{2}-\mathrm{O}\right)$, 1.68-1.65 (m, 2H, $\left.-\mathrm{CH}_{2}-\mathrm{CH}_{2}-\mathrm{Br}\right), 1.42-1.39\left(\left(\mathrm{~m}, 14 \mathrm{H},-\left(\mathrm{CH}_{2}\right)_{7}-\right)\right.$. 11-Bromoundecyl methacrylate $(1.3 \mathrm{~g}, 4 \mathrm{mmol}), N, N$-dimethyldodecylamine (0.85 g, $4 \mathrm{mmol}$ ) and $1 \mathrm{mg}$ of 2,6-di-tert-butyl-4-methylmethylphenol (as inhibitor of polymerization) were dissolved in $30 \mathrm{~mL}$ of chloroform and then heated at $60^{\circ} \mathrm{C}$ for $72 \mathrm{~h}$. On cooling the mixture was concentrated to $3-5 \mathrm{~mL}$ by vacuum and diethyl ether was added quickly. The clouded solution was kept at $-18^{\circ} \mathrm{C}$ for 1 day. The white precipitate was filtered off, redissolved in dichloromethane and reprecipitated by addition of diethyl ether. This reprecipitation procedure was repeated three times to give the desired pure ammonium compound (yield $=80 \%) .{ }^{1} \mathrm{H}-\mathrm{NMR}(400$ $\left.\mathrm{MHz}, \mathrm{CDCl}_{3}\right): 6.09(\mathrm{~d}, 1 \mathrm{H}, \mathrm{CHH}=\mathrm{C}), 5.54(\mathrm{~d}, 1 \mathrm{H}, \mathrm{CH} H=\mathrm{C}), 4.13(\mathrm{t}$, $\left.2 \mathrm{H},-\mathrm{CH}_{2}-\mathrm{O}\right), 3.51\left(\mathrm{t}, 4 \mathrm{H},-\mathrm{CH}_{2}-\mathrm{N}\right), 3.38\left(\mathrm{~s}, 3 \mathrm{H}, \mathrm{CH}_{3}-\mathrm{N}\right), 1.94(\mathrm{~s}, 3 \mathrm{H}$, $\left.-\mathrm{CH}_{3}-\mathrm{C}\right), 1.7-1.67\left(\mathrm{~m}, 4 \mathrm{H},-\left(\mathrm{CH}_{2} \mathrm{CH}_{2}\right)_{2} \mathrm{~N}, 1.66\left(\mathrm{~m}, 2 \mathrm{H},-\mathrm{CH}_{2}-\mathrm{CH}_{2}-\right.\right.$ O), 1.33-1.26 (m, 32H, $\left.-\mathrm{CH}_{2}\right), 0.86\left(\mathrm{t}, 3 \mathrm{H},-\mathrm{CH}_{3}-\right)$.

Polymerizable cluster. $\mathrm{Cs}_{2} \mathrm{Mo}_{6} \mathrm{Br}_{14}(1.97 \mathrm{~g}, 1 \mathrm{mmol})$ was stirred in $20 \mathrm{~mL}$ of acetone until complete dissolution. A solution of cation $(1 \mathrm{~g}, 2.20 \mathrm{mmol})$ was dissolved in dichloromethane and added dropwise to the previous cluster solution. The mixture was heated for $2 \mathrm{~h}$. The CsBr formed was filtered off and the organic solution was dried under vacuum. The product was obtained as a viscous oil. ${ }^{1} \mathrm{H}-\mathrm{NMR}\left(400 \mathrm{MHz}, \mathrm{CDCl}_{3}\right): 6.02(\mathrm{~d}, 2 \mathrm{H}$, $\mathrm{CHH}=\mathrm{C}), 5.48(\mathrm{~d}, 2 \mathrm{H}, \mathrm{CH} H=\mathrm{C}), 4.06\left(\mathrm{t}, 4 \mathrm{H},-\mathrm{CH}_{2}-\mathrm{O}\right), 3.20(\mathrm{t}$, $\left.8 \mathrm{H},-\mathrm{CH}_{2}-\mathrm{N}\right), 3.09\left(\mathrm{~s}, 6 \mathrm{H}, \mathrm{CH}_{3}-\mathrm{N}\right) 1.87\left(\mathrm{~s}, 6 \mathrm{H},-\mathrm{CH}_{3}-\mathrm{C}\right), 1.7-1.67$ $\left(\mathrm{m}, 8 \mathrm{H},-\left(\mathrm{CH}_{2} \mathrm{CH}_{2}\right)_{2} \mathrm{~N}\right), 1.66\left(\mathrm{~m}, 4 \mathrm{H},-\mathrm{CH}_{2}-\mathrm{CH}_{2}-\mathrm{O}\right), 1.24-1.16(\mathrm{~m}$, $\left.64 \mathrm{H},-\mathrm{CH}_{2}-\right)$, 0.86 (t, 6H, $-\mathrm{CH}_{3}-$ ). EDAX: no cesium; Mo: 33\%; $\mathrm{Br}$ : $67 \%$. Elemental anal. $\mathrm{C}_{58} \mathrm{H}_{114} \mathrm{~N}_{2} \mathrm{O}_{4} \mathrm{Mo}_{6} \mathrm{Br}_{14}$. Calcd: C, 26.82; H, 4.42; N, 1.08\%. Found: C, 26.84; H, 4.47; N, 1.13\%.

Polymerization. The polymerizable cluster was dissolved in freshly distilled methylmethacrylate (from $1 \mathrm{wt} \%$ to $50 \mathrm{wt} \%$ ). After addition of $0.2 \mathrm{wt} \%$ of the radical initiator $\mathrm{AIBN}$, the solutions were sonicated at $80{ }^{\circ} \mathrm{C}$ for 2 hours and then were placed in an oven at $60{ }^{\circ} \mathrm{C}$ for $48 \mathrm{~h}$. Transparent hybrid polymer pellets were then obtained. ${ }^{1} \mathrm{H}$ NMR spectra of dissolved pellets (except for the sample containing $50 \mathrm{wt} \%$ of cluster which lacks full solubility) in $\mathrm{CDCl}_{3}$ are provided in the ESI (Fig. $3 \mathrm{~s} \dagger$ ).

\subsection{Thermal analysis}

DSC measurements were realised at $10 \mathrm{~K} \mathrm{~min}^{-1}$ with a DSC 200 F3 Maia NETSCH apparatus. Thermogravimetric analysis was realised at $10 \mathrm{~K} \mathrm{~min}^{-1}$ on a TGA/DT Perkin Pyris Diamond. 


\subsection{Size exclusion chromatography (SEC) analysis}

SEC analysis was performed using a set of three columns: $2 \times$ ResiPore and $1 \times$ PL gel Mixed C (Polymer Labs.). The detection system was composed of a refractometer and a UV detector. Chloroform was used as eluent with a flow rate of $0.8 \mathrm{~mL} \mathrm{~min}^{-1}$. The elution profiles were analysed by the software Empower GPC module (Waters). Calculations were based on calibration curves obtained from polystyrene standards ranging from $200 \mathrm{~g} \mathrm{~mol}^{-1}$ up to $6 \times 10^{6} \mathrm{~g} \mathrm{~mol}^{-1}$. For the analysis, samples were refluxed $30 \mathrm{~min}$ in chloroform. The obtained solutions were filtered prior to injection.

\subsection{Structural characterization}

TEM characterizations (imaging and EDAX) were performed using a Hitachi H9000 NAR operating at $300 \mathrm{kV}$. A drop of the solution containing PM10 was deposited on TEM copper grids covered with a thin holey carbon film. For PM20 and PM50, layers of $100 \mathrm{~nm}$ were cut in the pellet by microtomy.

\subsection{Spectroscopic characterization}

Spectra were recorded directly on PM10 and PM50 pellets and on $\left[\left(n-\mathrm{C}_{4} \mathrm{H}_{9}\right)_{4} \mathrm{~N}\right]_{2}\left[\mathrm{Mo}_{6} \mathrm{Br}_{14}\right]$ powder deposited on a quartz substrate. Photoluminescence excitation maps were acquired at $293 \mathrm{~K}$ with a Jobin-Yvon Fluorolog 3 equipped with a CCD camera. CIE $(x ; y)$ coordinates of $\left[\left(n-\mathrm{C}_{4} \mathrm{H}_{9}\right)_{4} \mathrm{~N}\right]_{2} \mathrm{Mo}_{6} \mathrm{Br}_{14}, \mathrm{PM} 10$ and PM50 at $293 \mathrm{~K}$ under $425 \mathrm{~nm}$ excitation were determined from the photoluminescence spectra measured with this setup. The transient PL experiments have been carried out under 400 $\mathrm{nm}$ excitation using a Spectra-Physics Hurricane $\mathrm{X}$ laser system ( $82 \mathrm{fs}, 1 \mathrm{kHz}$ ) from $293 \mathrm{~K}$ to $20 \mathrm{~K}$. The collected emission was temporally detected with a streak camera (Hamamatsu C7700) coupled to an imaging spectrograph. The laser pump power impinging on sample was kept at $0.5 \mathrm{~mW}$. The CIE $(x ; y)$ coordinates of $\left[\left(n-\mathrm{C}_{4} \mathrm{H}_{9}\right)_{4} \mathrm{~N}\right]_{2} \mathrm{Mo}_{6} \mathrm{Br}_{14}$ and PM10 at various temperatures were determined from the photoluminescence spectra measured with this setup. The powder samples were placed near a GaAs temperature sensor on the cold finger of a helium cooled, continuous flow shielded optical cryostat. The quantum efficiency was estimated by using an integrating sphere of threeinch diameter $(76.2 \mathrm{~mm})$ and following the method described by De Mello et al. ${ }^{27}$

\section{Results and discussion}

\subsection{Synthesis strategy and nanocomposite analysis}

To obtain a $\mathbf{M}_{6}$ cluster containing material suitable for optical directed applications, we incorporated the molecular clusters in a poly-(methyl methacrylate) (PMMA) matrix and investigated the optical properties of the resulting hybrid material. PMMA was chosen for its excellent optical properties (i.e., transparency from the near-UV to the near-IR regions and damage resistance in the range needed for optical applications), good mechanical properties, thermal stability, and easy shaping. Our strategy is based on the introduction of polymerizable organic counter cations around the inorganic di-anionic cluster, followed by a copolymerization process with monomers. This approach was successfully used by $\mathrm{Wu}$ et al. who introduced several highly charged polyoxometalate (POM) groups in polymer matrices such as PMMA or polystyrene latex. ${ }^{6,28}$ But, such high anionic charge limits the maximum POM amount in the polymer, as inorganic contents of more than $10 \mathrm{wt} \%$ cause the loss of transparency of the hybrid. Note that this group did not report either solubility studies or the molecular weight of their hybrid. In our case, the low charge of the anionic cluster prevents this phenomenon and allows high cluster content of hybrid copolymer materials. The functional cluster was obtained by cationic metathesis from its cesium salt with a polymerizable surfactant: ${ }^{29}$ a dimethyl ammonium cation bearing two long alkyl chains from which one is terminated by a methacrylate function (Scheme 1). This cation was chosen because it allows to maintain very good miscibility between the monomer and the modified cluster. The identification and purity of the compound were assessed by ${ }^{1} \mathrm{H}$ NMR, EDAX and elemental analysis. Several copolymers containing 1, 10, 20 and $50 \mathrm{wt} \%$ (PM1, PM10, PM20 and PM50 respectively) were synthesized in bulk by radical polymerization using freshly distilled methylmethacrylate (MMA) and azobisisobutyronitrile (AIBN) as an initiator. All samples are fully homogeneous thanks to the dianionic character of the inorganic cluster. This is a central point to limit the cluster cross-linking ability and thus maintains good dispersion and a high transparency of the hybrid copolymer for cluster concentrations up to $50 \mathrm{wt} \%$. A neat PMMA sample (PM0) was also prepared for the sake of comparison.

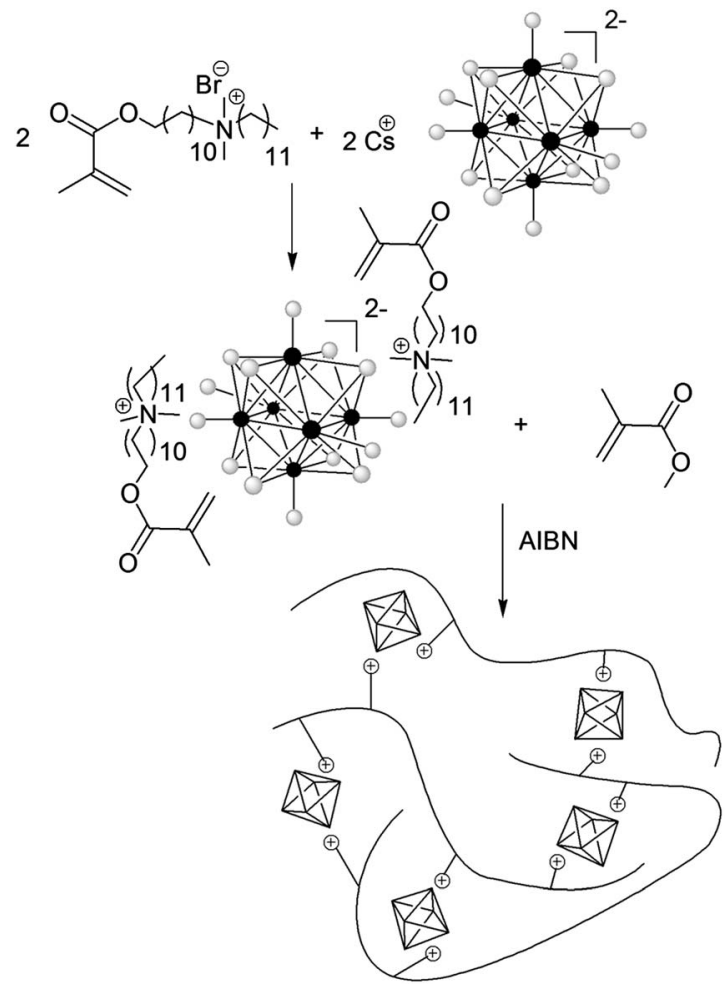

Scheme 1 Synthesis scheme of hybrid polymers. Black disks represent Mo atoms while grey ones are bromine atoms. 
Table 1 Composition and thermal data of synthesized hybrid polymers $^{a}$

\begin{tabular}{lclll}
\hline Sample & Cluster $(\mathrm{wt} \%)$ & $T_{\mathrm{d}}\left({ }^{\circ} \mathrm{C}\right)$ & $T_{\mathrm{g}}\left({ }^{\circ} \mathrm{C}\right)$ & $M_{\mathrm{w}}\left(\mathrm{g} \mathrm{mol}^{-1}\right)$ \\
\hline PM0 & - & 370 & 107 & 366000 \\
PM1 & 1 & 362 & 106 & 333000 \\
PM10 & 10 & 365 & 119 & 274000 \\
PM20 & 20 & 372 & 114 & $215000^{b}$ \\
PM50 & 50 & 375 & 105 & -
\end{tabular}

${ }^{a} T_{\mathrm{d}}$ : decomposition temperature; $T_{\mathrm{g}}$ : glass transition temperature; $M_{\mathrm{w}}$ : average molecular weight. ${ }^{b}$ Soluble part.

The influence of the cluster concentration on the copolymer thermal stability was studied by differential scanning calorimetry (DSC) and thermogravimetric analysis (TGA) by comparing the degradation temperatures of all samples under a $\mathrm{N}_{2}$ atmosphere (see ESI, Fig. 1s $\uparrow$ for TGA and DTA thermograms and Fig. $2 \mathrm{~s} \dagger$ for DSC thermograms). The main reaction stage corresponding to the maximum weight loss is located at $370{ }^{\circ} \mathrm{C}$ for pure PMMA which is in good accordance with reported values. ${ }^{25}$ As depicted in Table 1, the introduction of inorganic clusters does not modify significantly the thermal decomposition temperature or the glass transition temperature of the organic host. This phenomenon is attributed to the electrostatic nature of functional clusters which affords weak crosslinking ability. Indeed, the mobility of organic cation ammonium head around the anionic cluster core associated with the long alkyl chain between the ammonium and the methacrylate function strongly minimizes the crosslinking ability of the functional clusters. However, this crosslinking ability starts to be manifest with PM20 and PM50. Indeed, PM20 was only partially soluble in $\mathrm{CHCl}_{3}$ and $\mathrm{CDCl}_{3}$ while the determination of the average molecular weight by SEC of PM50 was not possible due to its complete lack of solubility in $\mathrm{CHCl}_{3}$. Nevertheless, all samples remain fully transparent (see Fig. 1 and Fig. $4 \mathrm{~s}_{\dagger} \dagger$ ) showing the high interest of this incorporation method as compared to the previously reported covalent strategy.

\subsection{Photophysical studies of cluster doped polymers}

Fig. 1 shows PM0, PM1 and PM10 pellets under daylight (Fig. 1a) and UV light (Fig. 1b, $\lambda_{\text {exc }}=365 \mathrm{~nm}$ ) (see ESI, Fig. $4 \mathrm{~s} \dagger$ or
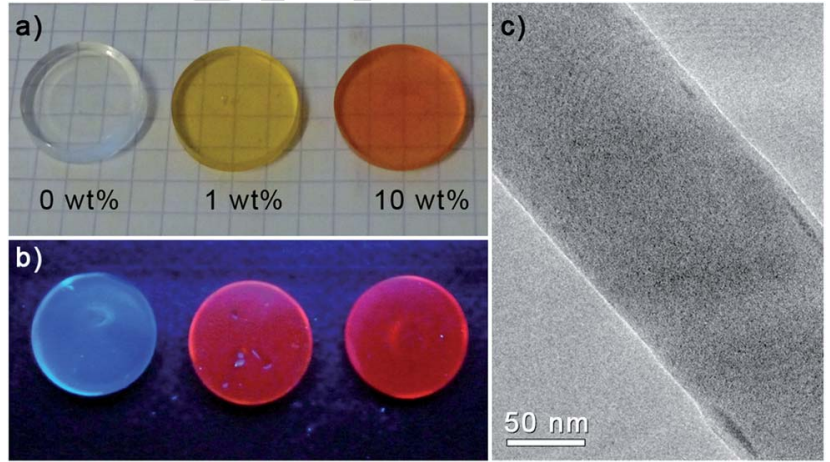

Fig. 1 Digital photographs of the $\mathrm{Mo}_{6}-\mathrm{PMMA}$ hybrid copolymer pellets under visible (a) and UV ( $\lambda_{\text {exc }}=365 \mathrm{~nm}$ ) light (b); (c) TEM picture of PM10 sample prepared as reported in ref. 30.
TOC for picture of PM20 and PM50 samples). The hybrid polymers are fully optically transparent materials even after 18 months of ageing, indicating the absence of macroscopic segregation of the inorganic moieties in the organic matrix. As demonstrated by Transition Electron Microscopy (TEM) studies, no segregation occurs at the nanoscale either. Indeed, Fig. 1c shows clearly that the clusters are homogeneously distributed within the copolymer matrix for PM10. A homogeneous distribution was also observed for PM20 and PM50 (see ESI, Fig. 6s and $7 \mathrm{~s} \dagger$ ) and was confirmed by energy dispersive X-ray spectrometry.

These last observations are of significant importance as they strongly suggest that the use of electrostatic interactions between clusters and a polymer matrix is (i) mandatory to prevent phase separation and (ii) a very pertinent and efficient alternative to the covalent strategy to design nanocomposites containing transition metal clusters at high concentration. ${ }^{23}$

The UV irradiation of samples shows the typical wide red emission of the transition metal cluster. Steady state and time resolved photoluminescence properties were investigated at various temperatures directly on the PM10 copolymer sample and compared to a known $\left[\left(n-\mathrm{C}_{4} \mathrm{H}_{9}\right)_{4} \mathrm{~N}\right]_{2}\left[\mathrm{Mo}_{6} \mathrm{Br}_{14}\right]$ powder sample deposited on a quartz plate to assess whether the intrinsic luminescence properties of the cluster were modified by its incorporation in the organic matrix. Fig. 2 presents the photoluminescence excitation maps (i.e. emission vs. excitation) for both samples at $293 \mathrm{~K}$.

Two important informations can be extracted from these maps: first, the observed luminescence does not depend on the excitation wavelength. Indeed, excitation anywhere in the cluster absorption band induces a broad emission centred

a)

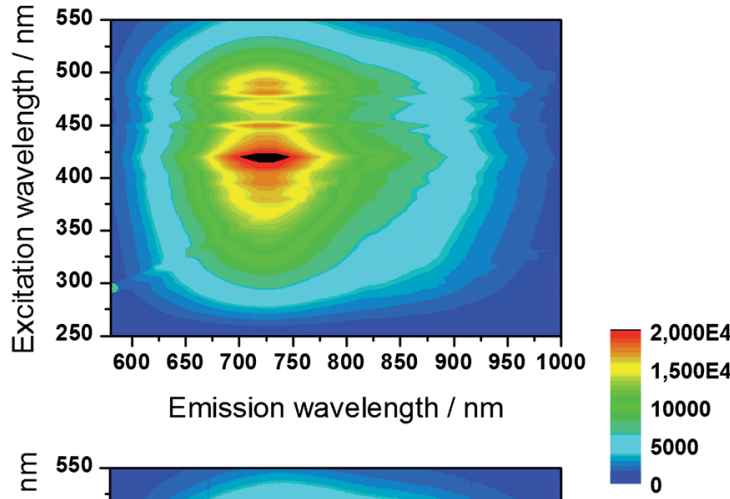

b)

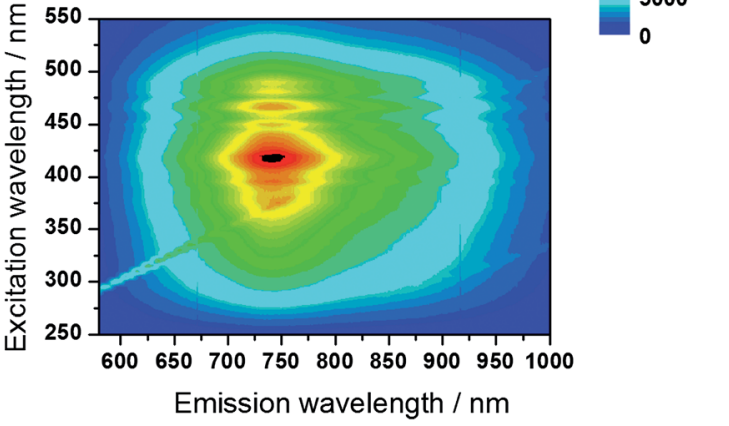

Fig. 2 Photoluminescence excitation maps measured at $293 \mathrm{~K}$ for (a) powdered $\left[\left(n-\mathrm{C}_{4} \mathrm{H}_{9}\right)_{4} \mathrm{~N}_{2}\left[\mathrm{Mo}_{6} \mathrm{Br}_{14}\right]\right.$ and (b) PM10. 
Table 2 Kinetics parameters obtained from phosphorescence emission decay measurements of $\left[\mathrm{Mo}_{6} \mathrm{Br}_{14}\right]^{2-}$ with $\left(\left(n-\mathrm{C}_{4} \mathrm{H}_{9}\right)_{4} \mathrm{~N}\right)^{+}$as a counter cation or embedded in the PMMA matrix $\left(\lambda_{\text {exc }}=400 \mathrm{~nm}\right)$, maximum of emission, and full width at half maximum (fwhm) at various temperatures

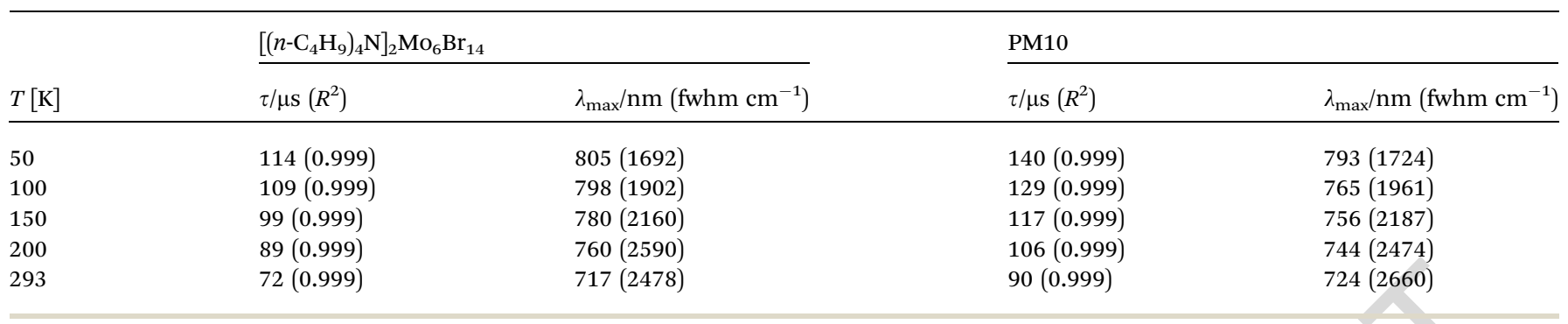

around $720 \mathrm{~nm}$. Second, the most intense emissions are obtained for excitation wavelengths between $415 \mathrm{~nm}$ and $425 \mathrm{~nm}$. Thus, using commercial purple $\left(\lambda_{\mathrm{em}}=405 \mathrm{~nm}\right)$ or blue $\left(\lambda_{\mathrm{em}}=445 \mathrm{~nm}\right)$ laser diode wavelength to excite the polymer sample leads to a decrease of the maximum intensity level of $12 \%$ or $23 \%$ respectively as compared to the maximum emission intensity obtained for the best excitation wavelength. Typical quantum yields of photoluminescence values of 0.22 , 0.25 and 0.21 for $\left[\left(n-\mathrm{C}_{4} \mathrm{H}_{9}\right)_{4} \mathrm{~N}\right]_{2}\left[\mathrm{Mo}_{6} \mathrm{Br}_{14}\right]$, PM10 and PM50, respectively, were measured at $293 \mathrm{~K}\left(\lambda_{\text {exc }}=425 \mathrm{~nm}\right)$. These values, which are consistent with literature data, ${ }^{13}$ reasonably corroborate that embodiment of clusters in PMMA with our method does not modify their ability to strongly emit light. To evaluate in a deeper manner the luminescence properties of the hybrids, time and temperature resolved laser induced phosphorescence emission spectra were collected upon excitation at $400 \mathrm{~nm}$ for $\left[\left(n-\mathrm{C}_{4} \mathrm{H}_{9}\right)_{4} \mathrm{~N}\right]_{2}\left[\mathrm{Mo}_{6} \mathrm{Br}_{14}\right]$ and PM10. Table 2 summarizes the kinetic parameters calculated from phosphorescence decay measurements at the maximum emission wavelength and at several temperatures for both samples, the temperature dependence of the emission maximum location, as well as the full width at half maximum (fwhm) of the emission signals. Fig. 3 illustrates the variation of these two last parameters by reporting the luminescence spectra at different temperatures. Cooling down from $293 \mathrm{~K}$ to $50 \mathrm{~K}$ induces a red shift of the emission maximum and a narrowing of the emission signal. These phenomena known to proceed with molybdenum octahedral transition metal cluster compounds evidence the existence of closely spaced excited states and that low energy emissive states become predominant at lower temperature. ${ }^{13}$ Although the emission width is relatively large, it is not as broad as previously reported either in the powder form or in the polymer. ${ }^{13,14}$ These differences compared to literature values are attributed to the experimental set-up. At this stage, we would like to emphasize that our set-up possesses a good and reasonably constant sensitivity on the studied wavelength area as compared to standard UV-Vis spectrophotometer detectors whose accuracy decreases dramatically after $700 \mathrm{~nm}$. Therefore, it allows us to study the temperature dependence emission maximum location and meaningful comparisons of fwhm values. Surprisingly, the emission fwhm of $\left[\left(n-\mathrm{C}_{4} \mathrm{H}_{9}\right)_{4} \mathrm{~N}\right]_{2^{-}}$ $\mathrm{Mo}_{6} \mathrm{Br}_{14}$ at $200 \mathrm{~K}$ is larger than that observed at $293 \mathrm{~K}$ but follows the normal narrowing trend on subsequent cooling. The embedment in the polymer does not produce the same artefact as the emission width seems to decrease in a quasi linear manner with the temperature.

In all cases, emission decay profiles were fitted to a single exponential decay and the goodness of the fit was evaluated by the $R^{2}$ value $(0.999)$. Lowering the temperature induces lengthening in the lifetime of the emissive species which is well known for such class of compounds (see ESI, Fig. $8 \mathrm{~s} \uparrow$ for emission decay profiles). ${ }^{31}$ However, as compared to previously reported lifetime values for $\left[\left(n-\mathrm{C}_{4} \mathrm{H}_{9}\right)_{4} \mathrm{~N}\right]_{2} \mathrm{Mo}_{6} \mathrm{Br}_{14}$ in degassed solution at $300 \mathrm{~K}(120-130 \mu \mathrm{s})$, the calculated cluster lifetime either in its powdered form or within the polymer is significantly shorter (72 $\mu$ s and $90 \mu$ s respectively). Molecular oxygen
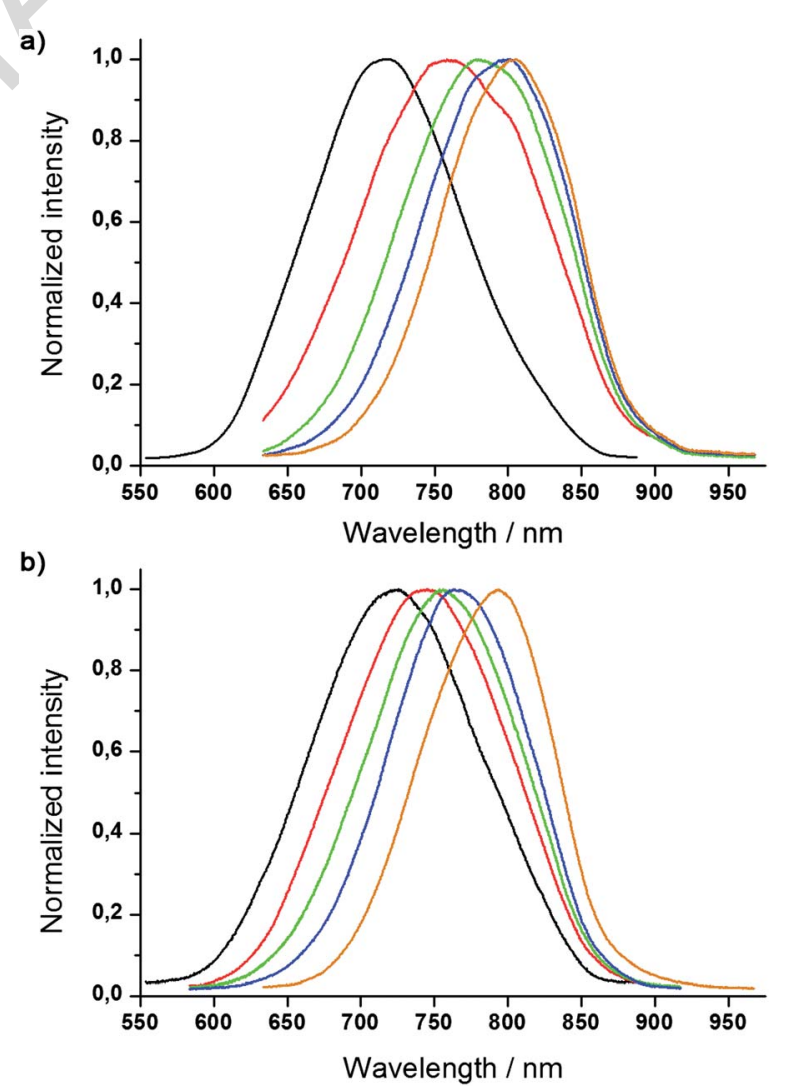

Fig. 3 Temperature dependent photoluminescence spectra of (a) powdered $\left.\left[\left(n-\mathrm{C}_{4} \mathrm{H}_{9}\right)_{4} \mathrm{~N}\right)\right]_{2}\left[\mathrm{Mo}_{6} \mathrm{Br}_{14}\right]$ and (b) PM10, observed for $\lambda_{\text {exc }}=$ $400 \mathrm{~nm}$ at $293 \mathrm{~K}$ (black), $200 \mathrm{~K}$ (red), $150 \mathrm{~K}$ (green), $100 \mathrm{~K}$ (blue) and $50 \mathrm{~K}$ (yellow). 
quenching of the cluster excited state is one possible explanation of this phenomenon. Recently, K. Kirakci et al. observed the quenching by molecular oxygen of $\left(n \mathrm{Bu}_{4} \mathrm{~N}\right)_{2}\left[\mathrm{Mo}_{6} \mathrm{I}_{8}\left(\mathrm{CF}_{3} \mathrm{CO}_{2}\right)_{6}\right]$ luminescence in solution, solid state or embedded at low percentage in a silica or polyurethane matrix, with subsequent production of singlet oxygen. ${ }^{32}$ Although this efficient quenching is well known since the beginning of the $90 \mathrm{~s},{ }^{33}$ they noticed a drop-down of the cluster luminescence lifetime with an increase in oxygen pressure. Taking into account that our cluster is more protected from oxygen once in the PMMA than in its powdered form, it seems logical that the calculated lifetime value is slightly higher in the polymer matrix than in its powdered form. Therefore, we can state from these measurements that the intrinsic properties of the molecular clusters are kept intact after their integration in the polymer matrix.

A red dye can be qualified as deep red if its $x$ coordinate in the Commission Internationale de l'Eclairage (CIE) chromaticity diagram is at least equal to $0.67 .^{34}$ To the best of our knowledge, the best deep red dyes used in optoelectronic applications are based on the phosphorescence of $\operatorname{Ir}(\mathrm{III})$ complexes which is tailored to the deep red area by subtle modifications of the metal coordination sphere. Slight modification of this coordination sphere induces drastic changes in the emission colour and/or efficiency of the $\operatorname{Ir}(\mathrm{III})$ complexes which is a major drawback for their direct integration in a polymer matrix (if one wants to preserve the native emission properties of the complexes).

Many groups are actually involved in taking control of such luminescence emission which can cover the whole visible range from deep blue ${ }^{35}$ to deep red. ${ }^{34}$ In our case, the preservation of the deep red character of cluster photoluminescence within the

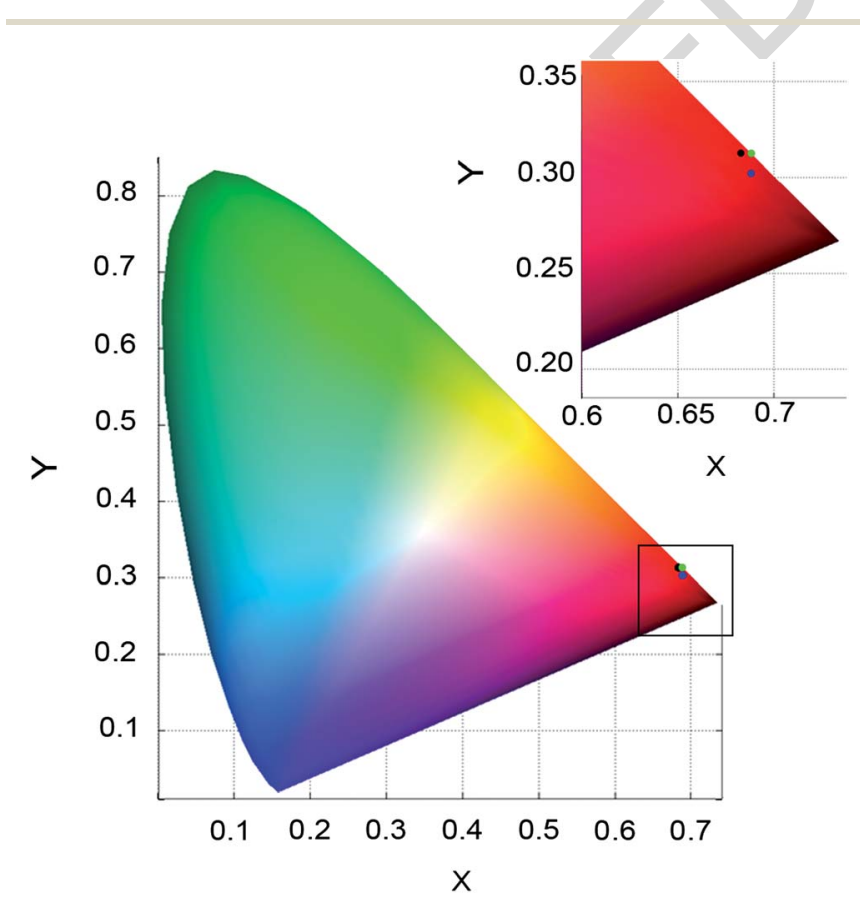

Fig. 4 Representation of $\left[\left(n-\mathrm{C}_{4} \mathrm{H}_{9}\right)_{4} \mathrm{~N}_{2} \mathrm{Mo}_{6} \mathrm{Br}_{14}\right.$ (green), $\mathrm{PM} 10$ (black circle) and PM50 (blue) $(x ; y)$ coordinates in the CIE chromaticity diagram at $293 \mathrm{~K}$ for $\lambda_{\mathrm{exc}}=425 \mathrm{~nm}$.
Table $3 \mathrm{CIE}(x ; y)$ coordinates of $\left[\left(n-\mathrm{C}_{4} \mathrm{H}_{9}\right)_{4} \mathrm{~N}\right]_{2} \mathrm{Mo}_{6} \mathrm{Br}_{14}$ and PM10 at various temperatures for $\lambda_{\text {exc }}=400 \mathrm{~nm}$

\begin{tabular}{llllll}
\hline & \multicolumn{2}{l}{$\left[\left(n-\mathrm{C}_{4} \mathrm{H}_{9}\right)_{4} \mathrm{~N}\right]_{2} \mathrm{Mo}_{6} \mathrm{Br}_{14}$} & & & PM10 \\
\cline { 5 - 6 }$T[\mathrm{~K}]$ & $x$ & $y$ & & $x$ & $y$ \\
\hline 20 & 0.731 & 0.269 & 0.732 & 0.268 \\
77 & 0.732 & 0.268 & 0.730 & 0.270 \\
100 & 0.731 & 0.269 & 0.730 & 0.270 \\
150 & 0.729 & 0.271 & 0.712 & 0.288 \\
200 & 0.727 & 0.273 & 0.711 & 0.289 \\
293 & 0.701 & 0.299 & 0.697 & 0.303 \\
\hline
\end{tabular}

hybrid polymer, as observed in its powdered form $(x=0.69 ; y=$ 0.31 ), was confirmed by the CIE chromaticity coordinates and is a major advantage compared to iridium based luminescent dyes. The coordinates $(x, y)$ were determined at the best excitation wavelength to observe the cluster luminescence, that is $425 \mathrm{~nm}$, for PM10 and PM50 at $293 \mathrm{~K}$ and are reported in the CIE diagram in Fig. 4. These two samples were also chosen to assess that the cluster concentration within the polymer matrix has very few or no influence on the observed photoluminescence colour. Let us point out at this stage that, to the best of our knowledge, this is the first time that such coordinates are reported for luminescent transition metal clusters.

Calculated values $(x=0.68 ; y=0.31)$ for PM10 and $(x=0.69$; $y=0.30$ ) for PM50 are consistent with the facts that (i) the deep red luminescence of the inorganic cluster core is preserved in the polymer matrix and (ii) that the cluster concentration has little influence on the observed colour. As previously stated, a decrease in temperature induces a red shift of the photoluminescence spectrum and as a consequence, a red shift of the $(x ; y)$ coordinates. Calculated coordinate values for different temperatures are gathered in Table 3 for $\left[\left(n-\mathrm{C}_{4} \mathrm{H}_{9}\right)_{4} \mathrm{~N}\right]_{2} \mathrm{Mo}_{6} \mathrm{Br}_{14}$ and PM10. Both samples follow the same trend. As an example, at $20 \mathrm{~K}, \mathrm{PM} 10$ coordinates are shifted to $(x=0.73 ; y=0.27)$.

\section{Conclusions}

We have described in this manuscript a simple way to obtain easily processable inorganic cluster-PMMA composites. We have shown that the $\mathrm{Mo}_{6}$ clusters maintain their intrinsic deep red luminescence properties while the polymer organic matrix fully maintains its processability, thanks to the di-anionic character of the $\mathrm{Mo}_{6}$ clusters. This simple method exploits the physical interactions between the organic and inorganic parts of the hybrid material. Remarkably, it demonstrates that transition metal clusters with a low anionic charge can be introduced at very high rates in a polymer matrix, and, that this matrix is homogeneous and highly stable even after several months of ageing. The deep red phosphorescence, characteristic of octahedral molybdenum clusters, occurs in the hybrid material on a large bandwidth extending from $600 \mathrm{~nm}$ to 850 $\mathrm{nm}$ at $293 \mathrm{~K}$ and becomes even deeper red upon cooling. As the cluster luminescence is not sensitive to its excitation wavelength, excitation anywhere in the cluster absorption band induces the observation of this saturated deep red colour. 
Finally, this method may be applied to all types of low charged anionic, luminescent or not, transition metal clusters and most of the polymer matrix. In the frame of the presented work, this new material shows promising prospects in telecom applications with the design of easy-to-handle NIR emitting trivalent rare earth metal containing materials whose luminescence is sensitized by transition metal clusters. ${ }^{23}$ Our advances in this particular matter will be reported in due course.

\section{Acknowledgements}

Authors thank Pr. O. Guillou and S. Freslon (TGA), Dr F. Camerel (DSC), Dr J. L. Audic (SEC) and E. Gautron for TEM characterization. This work was financially supported by Fondation Langlois and Region Bretagne (CREATE no. 5636). Part of the work was also supported by Region Pays de la Loire (NANOFONC program).

\section{Notes and references}

1 C. Feldmann, T. Juestel, C. R. Ronda and P. J. Schmidt, Adv. Funct. Mater., 2003, 13, 511; K. Binnemans, Chem. Rev., 2009, 109, 4283; J.-C. G. Bunzli and S. V. Eliseeva, J. Rare Earths, 2010, 28, 824; C. Zhang and J. Lin, Chem. Soc. Rev., 2012, 41, 7938.

2 E. Holder, N. Tessler and A. L. Rogach, J. Mater. Chem., 2008, 18, 1064.

3 S. Li, M. S. Toprak, Y. S. Jo, J. Dobson, D. K. Kim and M. Muhammed, Adv. Mater., 2007, 19, 4347; D. Sun, H. J. Sue and N. Miyatake, J. Phys. Chem. C, 2008, 112, 16002. 4 H. Song and S. Lee, Nanotechnology, 2007, 18, 055402.

5 C. Sanchez, G. J. de Soler-Illia, F. Ribot, T. Lalot, C. R. Mayer and V. Cabuil, Chem. Mater., 2001, 13, 3061; S. Gross, G. Trimmel, U. Schubert and V. Di Noto, Polym. Adv. Technol., 2002, 13, 254; Y. Han, Y. Xiao, Z. Zhang, B. Liu, P. Zheng, S. He and W. Wang, Macromolecules, 2009, 42, 6543.

6 H. L. Li, W. Qi, W. Li, H. Sun, W. F. Bu and L. X. Wu, Adv. Mater., 2005, 17, 2688.

7 M. K. Corbierre, N. S. Cameron, M. Sutton, S. G. J. Mochrie, L. B. Lurio, A. Rühm and R. B. Lennox, J. Am. Chem. Soc., 2001, 123, 10411; A. V. Fuchs and G. D. Will, Polymer, 2010, 51, 2119.

8 N. Wartenberg, O. Raccurt, D. Imbert, M. Mazzanti and E. Bourgeat-Lami, J. Mater. Chem. C, 2013, 1, 2061.

9 J. R. Long, L. S. McCarty and R. H. Holm, J. Am. Chem. Soc., 1996, 118, 4603.

10 K. Kirakci, S. Cordier and C. Perrin, Z. Anorg. Allg. Chem., 2005, 631, 411.

11 R. Chevrel and M. Sergent, in Topics in Current Physics, ed. O. Fischer and M. P. Maple, Springer Verlag, Berlin, Heidelberg, New York, 1982; D. G. Nocera and H. B. Gray, J. Am. Chem. Soc., 1984, 106, 824; J. M. Tarascon, F. J. Disalvo, D. W. Murphy, G. W. Hull, E. A. Rietman and J. V. Waszczak, J. Solid State Chem., 1984, 54, 204.

12 A. W. Maverick and H. B. Gray, J. Am. Chem. Soc., 1981, 103, 1298.
13 A. W. Maverick, J. S. Najdzionek, D. MacKenzie, D. G. Nocera and H. B. Gray, J. Am. Chem. Soc., 1983, 105, 1878.

14 M. N. Sokolov, M. A. Mihailov, E. V. Peresypkina, K. A. Brylev, N. Kitamura and V. P. Fedin, Dalton Trans., 2011, 40, 6375.

15 Y. Molard, F. Dorson, V. Circu, T. Roisnel, F. Artzner and S. Cordier, Angew. Chem., Int. Ed., 2010, 49, 3351; A. S. Mocanu, M. Amela-Cortes, Y. Molard, V. Circu and S. Cordier, Chem.Commun., 2011, 47, 2056; Y. Molard, A. Ledneva, M. Amela-Cortes, V. Circu, N. G. Naumov, C. Meriadec, F. Artzner and S. Cordier, Chem. Mater., 2011, 23, 5122 .

16 H. D. Selby, B. K. Roland and Z. Zheng, Acc. Chem. Res., 2003, 36, 933; D. Mery, C. Ornelas, M.-C. Daniel, J. Ruiz, J. Rodrigues, D. Astruc, S. Cordier, K. Kirakci and C. Perrin, C. R. Chim., 2005, 8, 1789; G. Prabusankar, Y. Molard, S. Cordier, S. Golhen, Y. Le Gal, C. Perrin, L. Ouahab, S. Kahlal and J. F. Halet, Eur. J. Inorg. Chem., 2009, 2153; F. Dorson, Y. Molard, S. Cordier, B. Fabre, O. Efremova, D. Rondeau, Y. Mironov, V. Circu, N. Naumov and C. Perrin, Dalton Trans., 2009, 1297.

17 M. A. Shestopalov, S. Cordier, O. Hernandez, Y. Molard, C. Perrin, A. Perrin, V. E. Fedorov and Y. V. Mironov, Inorg. Chem., 2009, 48, 1482.

18 S. Ababou-Girard, S. Cordier, B. Fabre, Y. Molard and C. Perrin, ChemPhysChem, 2007, 8, 2086; F. Grasset, F. Dorson, S. Cordier, Y. Molard, C. Perrin, A.-M. Marie, T. Sasaki, H. Haneda, Y. Bando and M. Mortier, Adv. Mater., 2008, 20, 143; F. Grasset, F. Dorson, Y. Molard, S. Cordier, V. Demange, C. Perrin, V. Marchi-Artzner and H. Haneda, Chem. Commun., 2008, 4729; F. Grasset, Y. Molard, S. Cordier, F. Dorson, M. Mortier, C. Perrin, M. Guilloux-Viry, T. Sasaki and H. Haneda, Adv. Mater., 2008, 20, 1710; S. Cordier, F. Dorson, F. Grasset, Y. Molard, B. Fabre, H. Haneda, T. Sasaki, M. Mortier, S. Ababou-Girard and C. Perrin, J. Cluster Sci., 2009, 20, 9; B. Fabre, S. Cordier, Y. Molard, C. Perrin, S. Ababou-Girard and C. Godet, J. Phys. Chem. C, 2009, 113, 17437; T. Aubert, F. Grasset, S. Mornet, E. Duguet, O. Cador, S. Cordier, Y. Molard, V. Demange, M. Mortier and H. Haneda, J. Colloid Interface Sci., 2010, 341, 201; D. Dybtsev, C. Serre, B. Schmitz, B. Panella, M. Hirscher, M. Latroche, P. L. Llewellyn, S. Cordier, Y. Molard, M. Haouas, F. Taulelle and G. Ferey, Langmuir, 2010, 26, 11283.

19 B. Moraru, N. Huesing, G. Kickelbick, U. Schubert, P. Fratzl and H. Peterlik, Chem. Mater., 2002, 14, 2732; S. Gross, V. Di Noto and U. Schubert, J. Non-Cryst. Solids, 2003, 322, 154.

20 J. H. Golden, H. B. Deng, F. J. Disalvo, J. M. J. Frechet and P. M. Thompson, Science, 1995, 268, 1463.

21 O. A. Adamenko, G. V. Lukova, N. D. Golubeva, V. A. Smirnov, G. N. Boiko, A. D. Pomogailo and I. E. Uflyand, Dokl. Phys. Chem., 2001, 381, 275; O. A. Adamenko, G. V. Loukova and V. A. Smirnov, Russ. Chem. Bull., 2002, 51, 994; N. D. Golubeva, O. A. Adamenko, G. N. Boiko, L. A. Petrova, Y. A. Ol'khov and A. D. Pomogailo, Inorg. Mater., 2004, 40, 306.

22 L. M. Robinson and D. F. Shriver, J. Coord. Chem., 1996, 37, 119. 
23 Y. Molard, C. Labbe, J. Cardin and S. Cordier, Adv. Funct. Mater., 2013, 23, 4821.

24 J. A. Jackson, M. D. Newsham, C. Worsham and D. G. Nocera, Chem. Mater., 1996, 8, 558; R. N. Ghosh, G. L. Baker, C. Ruud and D. G. Nocera, Appl. Phys. Lett., 1999, 75, 2885.

25 Y. Molard, F. Dorson, K. A. Brylev, M. A. Shestopalov, Y. Le Gal, S. Cordier, Y. V. Mironov, N. Kitamura and C. Perrin, Chem.-Eur. J., 2010, 16, 5613.

26 B. K. Roland, W. H. Flora, M. D. Carducci, N. R. Armstrong and Z. Zheng, J. Cluster Sci., 2003, 14, 449.

27 J. C. De Mello, F. H. Wittmann and R. H. Friend, Adv. Mater., 1997, 9, 230.

28 H. Li, W. Qi, H. Sun, P. Li, Y. Yang and L. Wu, Dyes Pigm., 2008, 79, 105; H. Li, P. Li, Y. Yang, W. Qi, H. Sun and L. Wu, Macromol. Rapid Commun., 2008, 29, 431; W. Qi and L. Wu, Polym. Int., 2009, 58, 1217.
29 J. Michas, C. M. Paleos and P. Dais, Liq. Cryst., 1989, 5, 1737; J. Eastoe, M. Summers and R. K. Heenan, Chem. Mater., 2000, 12, 3533.

30 A. Garreau, F. Massuyeau, S. Cordier, Y. Molard, E. Gautron, P. Bertoncini, E. Faulques, J. Wery, B. Humbert, A. Bulou and J.-L. Duvail, ACS Nano, 2013, 7, 2977.

31 T. Azumi and Y. Saito, J. Phys. Chem., 1988, 92, 1715.

32 K. Kirakci, P. Kubat, M. Dusek, K. Fejfarova, V. Sicha, J. Mosinger and K. Lang, Eur. J. Inorg. Chem., 2012, 3107.

33 J. A. Jackson, C. Turro, M. D. Newsham and D. G. Nocera, J. Phys. Chem., 1990, 94, 4500.

34 C.-H. Fan, P. Sun, T.-H. Su and C.-H. Cheng, Adv. Mater., 2011, 23, 2981.

35 C.-H. Yang, M. Mauro, F. Polo, S. Watanabe, I. Muenster, R. Fröhlich and L. De Cola, Chem. Mater., 2012, 24, 3684. 